\title{
Metagenomic data reveal diverse fungal and algal communities associated with the lichen
} symbiosis

Hayden Smith1, Francesco Dal Grande2,3, Lucia Muggia4, Rachel Keuler1, Pradeep K. Divakar5, Felix

1Department of Biology and M. L. Bean Life Science Museum, Brigham Young University, Provo, Utah, USA

2Senckenberg Biodiversity and Climate Research Centre (SBiK-F), Senckenberganlage 25, D60325 Frankfurt, Germany

3 LOEWE Centre for Translational Biodiversity Genomics (TBG), Senckenberganlage 25, D60325 Frankfurt, Germany

4University of Trieste, Department of Life Sciences, via Giorgieri 10, 34127-Trieste, Italy 5Departamento de Farmacología, Farmacognosia y Botánica, Facultad de Farmacia, Universidad Complutense de Madrid, 28040 Madrid, Spain

6Grainger Bioinformatics Center, Science \& Education, The Field Museum, Chicago, IL, USA 3Department of Ecology, Evolution and Diversity, Goethe Universität Frankfurt, Max-von-Laue Str. 11, D-60438 Frankfurt, Germany ${ }_{8}$ Science \& Education, The Field Museum, Chicago, IL, USA

*corresponding author: steve_leavitt@byu.edu

Francesco Dal Grande: https://orcid.org/0000-0002-1865-6281

Lucia Muggia: https://orcid.org/0000-0003-0390-6169

Pradeep K. Divakar: https://orcid.org/0000-0002-0300-0124

H. Thorsten Lumbsch: https://orcid.org/0000-0003-1512-835X

Steven D. Leavitt: https://orcid.org/0000-0002-5034-9724

Abstract: Lichens have traditionally been considered the symbiotic phenotype from the interactions of a single fungal partner and one or few photosynthetic partners. However, the lichen symbiosis has been shown to be far more complex and may include a wide range of other interacting organisms, including non-photosynthetic bacteria, accessory fungi, and algae. In this study, we analyzed metagenomic shotgun sequences to better characterize lichen mycobiomes. Specifically, we inferred the range of fungi associated within lichen thalli from five groups of lichens - horsehair lichens (mycobiont=Bryoria spp.), shadow lichens (taxa in Physciaceae), rock posies (Rhizoplaca spp.), rock tripes (Umbilicaria spp.), and green rock shields (Xanthoparmelia spp.). Metagenomic reads from the multi-copy nuclear ribosomal internal transcribed spacer region, the standard DNA barcode region for fungi, were extracted, clustered, and used to infer taxonomic assignments. Our data revealed diverse lichen-associated mycobiomes, and closely related mycobionts tended to have more similar mycobiomes. Many of the members of the lichen-associated mycobiomes identified here have not previously been found in association with lichens. We found little evidence supporting the ubiquitous presence of Cystobasidiales yeasts in macrolichens, although reads representing this putative symbiotic partner were found in samples of horsehair lichens, albeit in low abundance. Our study 
further highlights the ecosystem-like features of lichens, with partners and interactions far from being completely understood. Future research is needed to more fully and accurately characterize lichen mycobiomes and how these fungi interact with the major lichen components - the photo- and

44 mycobionts.

45 Key words: Cystobasidiomycetes, endolichenic fungi, genomics, holobiont, ITS, symbiosis

\section{Introduction}

Lichens have been iconic examples of symbiosis for the past 150 years (Honegger 2000). While the lichen was originally defined as a symbiotic relationship between a single fungus, the mycobiont, and a single or few species of green algae or cyanobacteria, the photobiont, studies have shown this is overly simplistic. It wasn't until the late 20 th century that in vitro studies began to look at other fungi as potentially lichen-associated organisms rather than mere contaminants (Petrini et al. 1990, Crittenden et al. 1995, Girlanda et al. 1997).

Advances in sequencing technologies have allowed for a deeper investigation into the diversity of

54 the lichen symbiosis, providing evidence that lichens are often composed of several fungal and green algal/cyanobacterial species forming a thallus with associated non-photosynthetic bacteria. Photobiont diversity can be shaped by reproductive and dispersal strategies of the mycobiont (Cao et al. 2015, Steinova et al. 2019), geography (Muggia et al. 2014, Werth and Sork 2014, Leavitt et al. 2015b), growth substrate (Bačkor et al. 2010, Leavitt et al. 2013b, Muggia et al. 2014) and macroclimate (Lu et al. 2018, Singh et al. 2018). The diversity of photobionts has been only recently explored by environmental DNA metabarcoding approaches and has focused on species within the Mediterranean basin to date (Moya et al. 2017, Dal Grande et al. 2018). In contrast to high-throughput sequencing approaches, traditional and largely applied DNA barcoding using Sanger sequencing was able to detect only the principal photobiont in the thalli (Paul et al. 2018). Additionally, many studies show that lichens are supported by a consortium of bacteria (Bates et al. 2011) that may change with substrate, altitude, and geography (Cardinale et al. 2012, Hodkinson et al. 2012, Fernandez-Brime et al. 2019). Potential functions of bacterial microbiomes include providing the host with nutrients, as well as protective and growthregulating functions (Cernava et al. 2017). Furthermore, study have also shown carbon exchange between lichen green algae and non-photosynthetic bacteria (Kono et al. 2017).

The lichen mycobiome - the fungal communities superficially associated and within the lichen thallus - can be made up of symptomatic lichenicolous fungi (Lawrey and Diederich 2003) and endolichenic fungi (Arnold et al. 2009, U'Ren J et al. 2010, Muggia et al. 2016). Lichenicolous fungi growing on lichen thalli, may or may not be parasitic, and can influence their host's morphology (Lawrey and Diederich 2003, U'Ren J et al. 2010, Fleischhacker et al. 2015). While some studies have found 
74 patterns in the lichen-associated mycobiome - for example, changing with altitude (Zhang et al. 2015,

75 Wang et al. 2016) - others have found little specificity between the lichen host and its associated mycobiome (Fleischhacker et al. 2015, Fernandez-Mendoza et al. 2017, Yu et al. 2018).

Recently basidiomycete yeasts have been called into question as a potential symbiotic partner in the lichen symbiosis with the discovery of Cystobasidiomycetes (Basidiomycota, Pucciniomycotina) in the cortices of lichens (Spribille et al. 2016). The presence of this group of fungi was previously discovered in association with two genera in the lichen-forming family Parmeliaceae, Hypogymnia and Usnea by (Millanes et al. 2016), who clarified the phylogenetic position and the monophyly of two

82 lichen-inhabiting species which were accommodated in the new genus Cyphobasidium. Later (Černajová 83 and Škaloud 2019) found Cystobasidiomycete yeasts in 95\% of Cladonia specimens collected across 84 Europe, though they were suggested to be either part of a superficial biofilm or living within the thallus 85 without associating with the cortex itself. In contrast, Lendemer et al. (2019) found them in just nine of 86 the 339 species investigated. There remains a question of how abundant and specific cystobasidiomycetes are in lichen assemblages, as well as how consistent the mycobiome might be among different lichenforming fungal species.

In terms of lichen photobionts, intrathalline photobiont diversity, e.g. multiple photobionts species within a single lichen thallus, has previously been observed in a number of lichen symbioses (Muggia et al. 2013, Dal Grande et al. 2014, Moya et al. 2017, Škaloud et al. 2018). In some cases, algae with different physiological performances are ever-present in lichen thalli potentially facilitating the success of these lichens in a wide range of habitats and geographic areas and/or in changing environmental conditions. However, Sanger sequencing has been shown to consistently fail to effectively generate DNA sequence data from lichen specimens when multiple Trebouxia lineages occur within a single lichen thallus (Paul et al. 2018), potentially biasing the perspective of lichen photobiont associations. The prevalence of intrathalline photobiont diversity in lichens remains unclear, impacting our understanding of its ecological and evolutionary significance.

As lichens are a model of symbiosis, there is a need to better characterize their microbial partners and associations. Therefore, we used existing datasets of metagenomic shotgun sequences in an attempt to: (1) characterize the lichen mycobiomes across multiple, phylogenetically distinct lichen groups, (2) assess the prevalence of basidiomycete yeast, a putative symbiotic partner in some lichen symbioses, and (3) investigate the potential for multiple species-level Trebouxia algal lineages within a single lichen

104 thallus.

\section{Materials and Methods:}


2.1 Taxon sampling - Our sampling focused on five morphologically distinct lichens groups - (i) rock posy lichens - the Rhizoplaca melanophthalma group (Fig. 1A \& B), (ii) green rock shield lichens Xanthoparmelia spp. (Fig. 1C \& D), (iii) rock tripe lichens - Umbilicaria spp., (iv) horse hair lichens Bryoria spp., and (iv) representatives from the mycobiont family Physciaceae (shadow lichens) (Table 1; Fig. 1). Rock posy lichens were represented by three distinct forms, all occurring in western North America: the vagrant taxon Rhizoplaca arbuscula (Fig. 1B; n=3), the vagrant/erratic taxon $R$. melanophthalma subsp. crispa $(\mathrm{n}=3)$, and the rock-dwelling taxon $R$. melanophthalma (Fig. 1A; $\mathrm{n}=3$ ) (Leavitt et al. 2013a). Green rock shield lichens were also represented by three distinct forms occurring in western North America: vagrant forms representing Xanthoparmelia aff. chlorochroa (Fig. 1D; n=3), isidiate (vegetative reproductive propagules) forms (Fig 1C; $=3$ ), and the sexually reproducing taxon $X$. neocumberlandia $(\mathrm{n}=3)$ (Leavitt et al. 2011). Rock tripe lichens were represented by two species collected in Spain, U. hispanica (3 populations) and U. pustulata (Fig 1G; 2 populations). For the rock tripe lichens, each sample represents metagenomic reads from a pooled population - 100 lichen thalli/population - (Dal Grande et al. 2017), rather than reads from an individual lichen thallus. Horsehair lichens were represented by two species, Bryoria fremontii (Fig. 1H; n=3) and B. tortuosa $(\mathrm{n}=3)$ (Velmala et al. 2009). The fungal family Physciaceae was represented by Mobergia calculiformis (Leavitt 16-697 [BRY-C]), Physcia sp. (Leavitt 17-611 [BRY-C]), Physciella sp. (Leavitt 17586 [BRY-C]), Oxnerella sp. (Leavitt 17-611 [BRY-C]), and Rinodina sp. (Leavitt 16-665 [BRY-C]). For rock posy lichens, green rock shield lichens, and representatives of Physciaceae, specimens were collected in dry conditions, with subsamples for molecular study removed within $24 \mathrm{~h}$ of collection and frozen at $-20{ }^{\circ} \mathrm{C}$ until DNA extraction. Sampling of horse hair and rock trips lichens were reported previously in (Spribille et al. 2016b) and (Dal Grande et al. 2017, Dal Grande et al. 2018), respectively. and sequencing methods (Table 1). Metagenomic reads from rock posy lichens (Rhizoplaca spp.) were initially reported in (Leavitt et al. 2016, Leavitt et al. 2019) and are available in NCBI's Short Read Archive under project PRJNA576709. For newly generated metagenomic reads from green rock shield lichens (Xanthoparmelia spp.) and representatives of Physciaceae, total genomic DNA was extracted

137 from a small portion of lichen thalli (comprised of the mycobiont, photobiont, and other associated 138 microbes) using the E.Z.N.A. Plant DNA DS Mini Kit (Omega Bio-Tek, Inc., Norcross, GA, USA) 139 following the manufacturers' recommendations. Total genomic DNA was prepared following the standard 140 Illumina whole genome sequencing (WGS) library preparation process using Adaptive Focused Acoustics 141 for shearing (Covaris), followed by an AMPure cleanup step. The DNA was then processed with the 
bioRxiv preprint doi: https://doi.org/10.1101/2020.03.04.966853; this version posted March 5, 2020. The copyright holder for this preprint Module (New England Biolabs) while using standard Illumina index primers. Libraries were pooled and sequenced with the HiSeq 2500 sequencer in high output mode at the DNA Sequencing Center, Brigham Young University, Provo, Utah, USA, using either 250 cycle paired-end reads or 300 cycle paired-end reads. Reads from green rock shield lichens (Xanthoparmelia spp.) and representatives from the mycobiont family Physciaceae are available in NCBI's Short Read Archive under project PENDING. The reads from the horsehair lichens are distinct in that these are transcriptomic reads (Spribille et al. 2016b), and we aimed to extract by-catch reads representing the internal transcribed spacer region (ITS). For the rock tripe lichens, each sample represents metagenomic reads from a pooled population (Pool-seq) - 100 lichen thalli/population - (Dal Grande et al. 2017), rather than reads from an individual lichen thallus.

Sequence Analysis - All reads were filtered using TRIMMOMATIC v0.33 (Bolger et al. 2014) before mapping to remove low quality reads and/or included contamination from Illumina adaptors using the following parameters: ILLUMINACLIP; LEADING:3; TRAILING:3; SLIDINGWINDOW:4:15; and MINLEN:36.

Previous studies have used assembled metagenomic contigs (Keepers et al. 2019) or mapping fungal reads to a fungal protein database (LaBonte et al. 2018) to provide crucial insight into fungal diversity in lichens and deciduous trees. Given the expected low coverage for fungi potentially co-occurring with a lichen thallus in short reads generated for this study, we chose to focus on the well-known repeat region which includes the standard fungal DNA barcode, the internal transcribed spacer (ITS) region of the nuclear ribosomal DNA (nrDNA) (Schoch et al. 2012). Across fungi, nrDNA copy number has been shown to vary considerably, ranging from tens to over 1400 copies per genome (Lofgren et al. 2019, Bradshaw et al. 2020). Furthermore, a comparatively robust and well-curated ITS database exists for fungi (Nilsson et al. 2019).

For reference ITS sequences, we used the UNITE QIIME v.8 dynamic release for fungi (Nilsson et al. 2019), filtered to include only sequences between 300 to 800 base pairs (reduced from 70,512 to 69,872 ITS sequences). Following recommendations by QIIME 2 developers, flanking regions, e.g., portions of the $18 \mathrm{~S}$ and/or $28 \mathrm{~S}$, with ITS sequences in the UNITE database were retained to reduce erroneous classifications when using the naïve Bayes classifier

172 Cystobasidiomycetes ITS sequences reported in (Spribille et al. 2016). All sampled lichens are reported to 173 associate with members of the genus Trebouxia as the primary lichen photobiont. In addition to assessing 174 fungal diversity in short reads generated from lichen thalli, we also included representative sequences for 175 each of the Trebouxia OTUs circumscribed in (Leavitt et al. 2015). Although lichens are known to 
bioRxiv preprint doi: https://doi.org/10.1101/2020.03.04.966853; this version posted March 5, 2020. The copyright holder for this preprint

associate with a broader range of algae than the core photobionts (Muggia et al. 2013), we did not assess accessory algae outside of Trebouxia.

For each metagenomic library, reads were mapped back to the composite ITS database using the Geneious read mapper in Geneious Prime (Kearse et al. 2012), implementing 'Medium-Low Sensitivity / Fast' sensitivity, iterated two times and saving all successfully mapped reads. Exploratory analyses with other read mapping approaches consistently recovered lower quantities of successfully mapped reads (data not shown). For each sample, metagenomic reads successfully mapped to the ITS references were imported into QIIME 2 (Bolyen et al. 2019). Reads were dereplicated using Vsearch 'dereplicatesequences' (Rognes et al. 2016), implementing default settings. The dereplicated sequences were clustered into de novo OTUs at a 97\% similarity in Vsearch using 'cluster-features-de-novo' (McDonald et al. 2012, Rognes et al. 2016). A naïve Bayes taxonomic classifier was trained using the same ITS reference library in QIIME 2 (Bokulich et al. 2018). The OTUs were then taxonomically classified using the trained naive Bayes trainer using QIIME 2 'feature-classifier classify-sklearn' at a 0.95 confidence level to minimize false positives, with all other settings at default (McKinney 2010, Pedregosa et al. 2011, Bokulich et al. 2018).

Of the estimated 2.2 to 3.8 million fungal species, only $3-8 \%$ are currently named (Hawksworth and Lücking 2017), and a much smaller portion are represented in available DNA reference libraries. Exploratory analyses of our lichen mycobiome data revealed poor taxonomic resolution below class levels for the majority of OTUs inferred here. Therefore, fungal OTUs that were classified at the class level were retained and others with less taxonomic resolution were excluded. Classification of fungal OTUs generated from reads mapped to the reference ITS database was summarized using the QIIME 'Taxa Barplot' feature (Caporaso et al. 2010). Data were managed, analyzed and visualized in R (R Core Team, 2019) using ggplot 2 (Wickham 2016) and tidyr (Wickham et al. 2019). To assess the similarity of lichen mycobiomes within and among phylogenetically distinct mycobionts, a principle component analysis (PCA) was performed on the class-level taxonomic classification using tidyr (Wickham et al. 2019), with the command 'prcomp'. While formal species-level taxonomy in the lichen photobiont Trebouxia remains woefully inadequate (Muggia et al. in review), DNA sequence data representing a wide range of putatively species-level lineages, with accompanying provisional names, is available (Leavitt et al. 2015). For Trebouxia (photobiont) OTUs, the classified reads were filtered at the 'species'

205 level, based on the 69 putative species-level OTUs from Leavitt et al. (2015), using QIIME 'taxa filter206 table' command to determine the range of Trebouxia diversity occurring within each sample. All code 207 used in this experiment is provided as supplementary file S1. 
bioRxiv preprint doi: https://doi.org/10.1101/2020.03.04.966853; this version posted March 5, 2020. The copyright holder for this preprint

\section{Results:}

Between 0.41 and $3.68 \%$ of metagenomic reads were mapped back to the ITS reference library (Table 1). The primary lichen symbionts, the mycobiont and photobiont, accounted for ca. 50\% of all ITS reads extracted from the metagenomic data on average (Fig. 2A). The relative abundance of ITS reads

214 representing the mycobiont (inferred at the class level, e.g., Lecanoromycetes) was between 5.20\% to

$21580.31 \%$ of ITS reads, with an average relative abundance of $40 \%$. The relative abundance of reads from

216 the photobiont, Trebouxia spp., comprised between $0.68 \%$ to $35.09 \%$ of ITS reads, with an average

217 relative abundance of ca. $10 \%$.

Lichen-associated fungi made up a large fraction of metagenomic reads, representing a total of 22 different fungal classes (Fig. 2B). Both in terms of abundance and diversity, Ascomycota OTUs were most frequently recovered and represented by 10 classes, excluding the mycobiont class Lecanoromycetes, followed by Basidiomycota represented by seven classes. Chytridiomycota (represented by two classes), Glomeromycota (one class), and Kickxellomycota (one class) were found in low abundance and diversity (at the class level) (abbreviated Chy., Glo., and Kic., respectively, in Fig. 3). Overall, reads from Cystobasidiomycete yeasts were poorly represented in extracted ITS reads, found in only 5 of the 35 samples. Notably, ITS by-catch from the Bryoria fremontii transcriptomic data from which lichen-associated yeasts were first reported in the cortex, resulted in the highest abundance of reads potentially representing cystobasidiomycete yeasts, with an average relative abundance of $0.7 \%$ of the ITS reads in the three $B$. fremontii samples. In the remaining two samples with evidence of Cystobasidiomycete yeasts, Physcia biziana and one sample of Xanthoparmelia chlorochroa (818F), had an average relative abundance of $0.03 \%$.

Closely related mycobionts tended to have more similar mycobiomes (Fig. 4). The PCA revealed a general pattern of mycobiome similarity among samples representing mycobiont species, and relatively high levels of similarity among mycobiont congeners (Figs. $3 \& 4$ ). Differences in lichen mycobiomes are most distinct among different genera of lichen-forming fungi.

Evidence supporting intrathalline Trebouxia photobiont diversity was observed in 16 of the 29 samples (Umbilicaria samples not considered - see methods above) (Fig. 5). Thalli from representatives of Physciaceae and Rhizoplaca (rock posy lichens) consistently contained a dominant Trebouxia lineage with $>90 \%$ relative abundance. Green rock shield lichens (Xanthoparmelia spp.) associated with a wider range of Trebouxia species, with evidence of multiple Trebouxia species occurring within an individual

240 lichen thallus. Two of the six Bryoria samples also provided evidence of multiple Trebouxia species 241 occurring within individual thalli. Intrathalline photobiont diversity in Umbilicaria pustulata and U.

242 hispanica is described in detail in (Paul et al. 2018). Here we report photobiont diversities within 
243 populations of Umbilicaria spp. (each sample represents 100 pooled individual thalli from a single

244 population).

\section{Discussion}

The broad range of organisms involved in lichen symbioses has recently been highlighted, including diverse algae (Muggia et al. 2013, Moya et al. 2017), non-photosynthetic bacteria (Cardinale et al. 2006, Grube et al. 2009, Hodkinson and Lutzoni 2009), and broad range of fungal lineages (Lawrey and Diederich 2003, Spribille et al. 2016, Tuovinen et al. 2019). Using data mining of fungal ITS reads from metagenomic shotgun sequences of lichen thalli, we provide a coarse snapshot of unexpectedly diverse lichen-associated mycobiomes (Fig. 3). The accessory fungi accounted for a significant proportion of ITS reads extracted from metagenomic shotgun sequencing data (Fig. 2B), spanning multiple phyla dominated by Ascomycota and Basidiomycota but with representatives from Entomophthoromycota, Chytridiomycota, Glomeromycota, and Kickxellomycota. While a number of the class-level lineages inferred from metagenomic ITS reads are known to associate with lichens, e.g., Agaricomycetes, Dothideomycetes, Eurotiomycetes, and Sordariomycetes, other classes do not include fungi previously known to associate with lichens, e.g. Entomophthoromytes. In contrast to recent studies highlighting the role of two basidiomycete lineages in some lichen symbioses, Tremella (Tuovinen et al. 2019) and Cystobasidiomycete yeasts (Spribille et al. 2016), these were recovered only sporadically and in very low abundance in our samples. Nonetheless, these basidiomycete fungi have often been reported as lichenicolous, growing on a number of lichen hosts (Diederich 1996, Millanes et al. 2016). Below we discuss the potential implications of our findings and potential ways to move forward.

The relative importance of host versus environment in determining the diversity of the lichen mycobiome is poorly understood. However, lichen mycobiomes appear to comprise stable and transient guilds, which to some extent correlate with the ecological conditions of the lichen habitats. (FernándezMendoza et al. 2017) proposed three ecological components of lichen mycobiomes: (i) generalist taxa common to the environmental pool of bio- and saprotrophic fungi, (ii) lichenicolous and endolichenic fungi specific to each genus/species, and (iii) species which disperse and possibly germinate on, among, and within lichen thalli, but do not play a definite ecological role in the lichen community. Our results

272 indicate that closely related mycobionts tend to have more similar mycobiomes (Fig. 4), even in cases 273 where distinct lichens commonly co-occur, e.g. green rock shields (mycobiont = Xanthoparmelia spp.) 274 and rock posies (mycobiont = Rhizoplaca spp.). These data support the perspective that a significant 275 component of the lichenicolous and endolichenic fungal community are specific to different mycobiont 276 genera/species. 
Broadly speaking, Sordariomycetes and Leotiomycetes are frequently recovered from lichens occurring in humid, temperate, boreal environments, and Antarctic environments, representing lineages closely related to plant endophytes (Arnold et al. 2009, U'Ren J et al. 2010, Yu et al. 2018). In contrast, Dothideomycetes and Eurotiomycetes are more frequently associated with rock-inhabiting lichens (Muggia and Grube 2018). In rock-inhabiting lichens, the lichen-associated fungi are usually melanized fungi comprising unknown and known hyphomycetous lineages which show close affinities to some symptomatic lichenicolous fungi, extremotolerant rock-inhabiting fungi from oligotrophic environments and to plant and animal pathogenic black yeasts (Muggia et al. 2016, Muggia and Grube 2018). These fungi are widely known as black fungi because they accumulate melanins in their cell walls, which enable them to grow in oligotrophic environments and resist multiple abiotic stresses, such as high doses of radiation, desiccation, temperature extremes (Gostinčar et al. 2009). Black fungi are, therefore, usually recognized as (poly)extremotolerant organisms.

In our study, different lichen genera tended to associate with distinct fungal communities (Fig. 3). These relationships appear to be consistent across relatively broad geographic areas, at least for some lichens. Our results indicated that the mycobiomes of green rock shield (mycobiont = Xanthoparmelia spp.) and rock posy (mycobiont $=$ Rhizoplaca spp.) populations occurring across western North America were strikingly different (Fig. 3). While disparate morphologies of rock posy lichens had relatively consistent mycobiomes, even in specimens collected across geographically distinct populations, differences in mycobiome communities of green rock shield lichens with different morphologies and reproductive strategies were observed (Fig. 3). However, within green rock shield lichens, vagrant (obligately unattached specimens), rock-dwelling isidiate (reproducing via specialized asexual propagules), and rock-dwelling sexually reproducing forms tended to associate with distinct fungal communities, albeit with limited sample sizes. Additional research will be required to more fully assess if distinct mycobiomes, or core subsets of the mycobiome, within lichen groups are maintained across geographic and ecological distances. If differing core mycobiome communities are found in association with distinct mycobionts, at what level does this specificity exist, e.g., mycobiont species, genera, etc.? Directed experimental design and broader sampling will be required to determine how lichen mycobiomes are structured at different evolutionary scales relative to the predominant mycobiont.

When investigating the potential for photobiont (Trebouxia spp.) diversity within a single lichen

$307=$ Rhizoplaca spp.) and shadow lichens (members of the mycobiont family Physciaceae), tend to associate 308 with a single/one dominant Trebouxia lineage. For rock tripe lichens (mycobiont = Umbilicaria spp.),

309 (Paul et al. 2018) observed a single pattern of a single dominant Trebouxia lineage per thallus. However, 310 the metagenomic reads from rock tripe lichens used in the present study were generated from multiple 
311 lichen thalli pooled into a single population per site, and we were unable to corroborate these results

312 reported. In contrast, it appears that green rock shield lichen (mycobiont = Xanthoparmelia) thalli

313 consistently harbor multiple, distinct Trebouxia lineages. A previous study characterizing Trebouxia

314 diversity associating with members of the mycobiont family Parmeliaceae also demonstrated distinct

315 patterns of photobiont association between Rhizoplaca spp. and Xanthoparmelia spp., with

316 Xanthoparmelia spp. associating with a much wider range of photobionts than Rhizoplaca spp. (Leavitt et

317 al. 2015). Furthermore, the two mycobiont genera consistently associated with distinct Trebouxia lineages

318 with very little overlap, and these results were corroborated by our findings (Fig. 5). By explicitly taking

319 the potential for intrathalline photobiont diversity into consideration, we anticipate novel insight into

320 different strategies of lichen symbiosis.

While our study provides novel insight into lichen symbioses and impetus for future research, there are a number of methodological limitations that potentially bias the results presented here. Metagenomic reads from lichen-forming fungi are expected to be dominated by reads from the major lichen symbionts, the myco- and photobionts (Pizarro 2019), and other eukaryotic microbial diversity associated with lichen thalli is likely found in much lower abundance in metagenomic short read data. Therefore, here we opted to target fungal reads from the multi-copy nuclear ribosomal cistron (nrDNA) in order to identify fungi that might be found in low relative abundance and likely overlooked using single copy regions and metagenomic binning approaches. Furthermore, with portions of the nrDNA are highly conserved across fungi, we focused on the highly variable internal transcribed spacer region (ITS) due to the high variability and well-curated reference database (Schoch et al. 2012, Nilsson et al. 2019). However, nrDNA copy number varies by orders of magnitude across fungi, from tens to over 1400 copies per genome (Lofgren et al. 2019, Bradshaw et al. 2020). Therefore, the relative abundance of fungal groups inferred in this study (e.g., Fig. 3) does not accurately depict true relative abundance of lichenassociated fungi given the potential for a very wide range of nrDNA copy number of these fungi.

Another source of potential bias is from the bioinformatic pipeline implemented here. Even using relatively well-established pipelines of ITS amplicon-based metagenomic reads, bioinformatics analysis pipelines have been shown to vary greatly in their relative performance and accuracy in characterizing fungi from metagenomic data (Anslan et al. 2018). We would anticipate that the data mining approach implemented in this study may have introduced a number of unexpected and difficult to identify artifacts, ranging from potentially over- and underrepresenting different fungal lineages to erroneous taxonomic 342 present study, a significant proportion of reads from green rock shield lichens were assigned to the class 343 Entomophthoromytes, a lineage that has not previously been found in association with lichens. Whether 344 the inferred prevalence of Entomophthoromytes is biased by copy number variation of the nrDNA, an 
345 artifact of read mapping to the UNITE database, etc., or accurately represents a novel finding is unclear.

346 Furthermore, only a small fraction of the estimate 2.2-3.8 million fungal species are represented in

347 currently available curated databases. Therefore, in fungal metabarcoding studies, a large proportion of

348 operational taxonomic units (OTUs) cannot be identified to any meaningful taxonomic, and these

349 unclassifiable species hypotheses, or 'dark taxa', remain problematic in metagenomic studies of fungi

350 (Nilsson et al. 2019).

Taken together, our results highlight, on the one hand, the presence of a highly diverse, seemingly

352 lichen host-specific mycobiome, and on the other hand, the risk of applying overly simplistic techniques -

353 such as phylum rank classifications - to tackle the diversity of these lichen-associated fungal

354 communities.

355

\section{Acknowledgements}

357 We gratefully acknowledge the fruitful discussion with Toby Spribille, Diane Haughland, and Trevor

358 Goward. This research was supported by College of Life Sciences at Brigham Young University, Provo,

359 Utah, USA. We thank Ed Wilcox, DNA Sequencing Center, Brigham Young University, Provo, Utah,

360 USA, for help with sequencing. 


\section{References}

Anslan S, Nilsson RH, Wurzbacher C, Baldrian, P, Leho, T, Bahram, M (2018) Great differences in performance and outcome of high-throughput sequencing data analysis platforms for fungal metabarcoding. MycoKeys, pp 29-40.

Arnold AE, Miadlikowska J, Higgins KL, Sarvate SD, Gugger P, Way A, Hofstetter V, Kauff F, Lutzoni F (2009) A phylogenetic estimation of trophic transition networks for ascomycetous fungi: are lichens cradles of symbiotrophic fungal diversification? Syst Biol 58, 283-297.

Bačkor M, Peksa O, Škaloud P, Bačkorová M (2010) Photobiont diversity in lichens from metal-rich substrata based on ITS rDNA sequences. Ecotoxicology and Environmental Safety 73, 603-612.

Bates, ST, Cropsey GW, Caporaso JG, Knight R, Fierer N (2011) Bacterial communities associated with the lichen symbiosis. Appl Environ Microbiol 77, 1309-1314.

Bokulich NA, Kaehler, BD, Rideout, JR, Dillon, M, Bolyen, E, Knight, R, Huttley, GA, Gregory Caporaso J (2018) Optimizing taxonomic classification of marker-gene amplicon sequences with QIIME 2's q2-feature-classifier plugin. Microbiome 6, 90.

Bolger, AM, Lohse M, Usadel B (2014) Trimmomatic: a flexible trimmer for Illumina sequence data. Bioinformatics 30, 2114-2120.

Bolyen E, Rideout JR, Dillon MR, et al. (2019) Reproducible, interactive, scalable and extensible microbiome data science using QIIME 2. Nat Biotechnol 37, 852-857.

Bradshaw M, Grewe F, Thomas A, Harrison CH, Lindgren H, Muggia L, St Clair LL, Lumbsch HT, Leavitt SD (2020) Characterizing the ribosomal tandem repeat and its utility as a DNA barcode in lichen-forming fungi. BMC Evolutionary Biology 20, 2.

Cao S, Zhang F, Liu C, Hao Z, Tian Y, Zhu L, Zhou Q (2015) Distribution patterns of haplotypes for symbionts from Umbilicaria esculenta and $U$. muehlenbergii reflect the importance of reproductive strategy in shaping population genetic structure. BMC Microbiol 15, 212.

Caporaso JG, Kuczynski J, Stombaugh J et al. (2010) QIIME allows analysis of high-throughput community sequencing data. Nat Methods 7, 335-336.

Cardinale M, Grube M, Castro Jr JV, Muller H, Berg G (2012) Bacterial taxa associated with the lung lichen Lobaria pulmonaria are differentially shaped by geography and habitat. FEMS Microbiol Lett 329, 111-115.

Cardinale M, Puglia AM, Grube M (2006) Molecular analysis of lichen-associated bacterial communities. FEMS Microbiology Ecology 57, 484-495. 
Černajová I, Škaloud P (2019) The first survey of Cystobasidiomycete yeasts in the lichen genus

Cladonia; with the description of Lichenozyma pisutiana gen nov, sp nov. Fungal Biology 123, 625-637.

Cernava T, Erlacher A, Aschenbrenner IA, Krug L, Lassek C, Riedel K, Grube M, Berg G (2017) Deciphering functional diversification within the lichen microbiota by meta-omics. Microbiome 5, 82.

Crittenden PD, David JC, Hawksworth DL, Campbell FS (1995) Attempted isolation and success in the culturing of a broad spectrum of lichen-forming and lichenicolous fungi. The New Phytologist 130, 267-297.

Dal Grande F, Alors D, Divakar PK, Bálint M, Crespo A, Schmitt I (2014) Insights into intrathalline genetic diversity of the cosmopolitan lichen symbiotic green alga Trebouxia decolorans Ahmadjian using microsatellite markers. Molecular Phylogenetics and Evolution 72, 54-60.

Dal Grande F, Rolshausen G, Divakar PK, Crespo A, Otte J, Schleuning M, Schmitt I (2018) Environment and host identity structure communities of green algal symbionts in lichens. New Phytologist 217, 277-289.

Dal Grande F, Sharma R, Meiser A, Rolshausen G, Büdel B, Mishra B, Thines M, Otte J, Pfenninger M, Schmitt I (2017) Adaptive differentiation coincides with local bioclimatic conditions along an elevational cline in populations of a lichen-forming fungus. BMC Evolutionary Biology 17, 93.

Diederich P, 1996 The lichenicolous heterobasidiomycetes. Bibliotheca Lichenologica 61, 1-198.

Fernandez-Brime S, Muggia L, Maier S, Grube M, Wedin M (2019) Bacterial communities in an optional lichen symbiosis are determined by substrate, not algal photobionts. FEMS Microbiol Ecol 95.

Fernandez-Mendoza F, Fleischhacker A, Kopun T, Grube M, Muggia L (2017) ITS1 metabarcoding highlights low specificity of lichen mycobiomes at a local scale. Mol Ecol 26, 4811-4830.

Fernández-Mendoza F, Fleischhacker A, Kopun T, Grube M, Muggia L (2017) ITS1 metabarcoding highlights low specificity of lichen mycobiomes at a local scale. Molecular Ecology 26, 4811-4830.

Fleischhacker A, Grube M, Kopun T, Hafellner J, Muggia L (2015) Community analyses uncover high diversity of lichenicolous fungi in alpine habitats. Microb Ecol 70, 348-360.

Girlanda M, Isocrono D, Bianco C, Luppi-Mosca A (1997) Two foliose lichens as microfungal ecological niches. Mycologia 89, 531-536.

Gostinčar C, Grube M, De Hoog S, Zalar P, Gunde-Cimerman N (2009) Extremotolerance in fungi: evolution on the edge. FEMS Microbiology Ecology 71, 2-11.

Grube M, Cardinale M, de Castro Jr JV, Muller H, Berg G (2009) Species-specific structural and functional diversity of bacterial communities in lichen symbioses. ISME J 3, 1105-1115. 
Hawksworth DL, Lücking R (2017) fungal diversity revisited: 22 to 38 million species. Microbiol Spectr 5.

Hodkinson B, Lutzoni F (2009) A microbiotic survey of lichen-associated bacteria reveals a new lineage from the Rhizobiales. Symbiosis 49, 163-180.

Hodkinson BP, Gottel NR, Schadt CW, Lutzoni F (2012) Photoautotrophic symbiont and geography are major factors affecting highly structured and diverse bacterial communities in the lichen microbiome. Environ Microbiol 14, 147-161.

Honegger R, 2000 Simon Schwendener (1829-1919) and the dual hypothesis of lichens. The Bryologist 103, 307-313.

Kearse M, Moir R, Wilson A, Stones-Havas S, Cheung M, Sturrock S, Buxton S, Cooper A, Markowitz S, Duran C, Thierer T, Ashton B, Meintjes P, Drummond A (2012) Geneious Basic: An integrated and extendable desktop software platform for the organization and analysis of sequence data. Bioinformatics 28, 1647-1649.

Keepers KG, Pogoda CS, White KH, Anderson Stewart CR, Hoffman JR, Ruiz AM, McCain,CM,

Kono M, Tanabe H, Ohmura Y, Satta Y, Terai Y (2017) Physical contact and carbon transfer between a lichen-forming Trebouxia alga and a novel Alphaproteobacterium. Microbiology 163, 678-691. and epiphytic fungal diversity in short-read genomic data from deciduous trees .Fungal Ecology 35, $1-9$.

Lawrey JD, Diederich P (2003) Lichenicolous fungi: interactions, evolution, and biodiversity. The Bryologist 106, 80-120.

Leavitt SD, Fernández-Mendoza F, Pérez-Ortega S, Sohrabi M, Divakar PK, Vondrák J, Lumbsch HT, St. Clair LL (2013)a Local representation of global diversity in a cosmopolitan lichen-forming fungal species complex (Rhizoplaca, Ascomycota). Journal of Biogeography 40, 1792-1806.

Leavitt SD, Nelsen MP, Lumbsch HT, Johnson LA, St Clair LL (2013b) Symbiont flexibility in subalpine rock shield lichen communities in the Southwestern USA .The Bryologist 116, 149-161. approaches Scientific Reports 6, 22262. 
Leavitt SD, Johnson LA, Goward T, St Clair LL (2011) Species delimitation in taxonomically difficult lichen-forming fungi: An example from morphologically and chemically diverse Xanthoparmelia (Parmeliaceae) in North America. Molecular Phylogenetics and Evolution 60, 317-332.

Leavitt SD, Keuler R, Newberry CC, Rosentreter R, St Clair LL (2019) Shotgun sequencing decades-old lichen specimens to resolve phylogenomic placement of type material. Plant and Fungal Systematics 64, 237-247

Leavitt SD, Kraichak E, Nelsen MP, Altermann S, Divakar PK, Alors D, Esslinger TL, Crespo A,

Lendemer JC, Keepers KG, Tripp EA, Pogoda CS, McCain CM, Kane NC (2019) A taxonomically broad metagenomic survey of 339 species spanning 57 families suggests cystobasidiomycete yeasts are not ubiquitous across all lichens. Am J Bot 106, 1090-1095.

Lofgren LA, Uehling JK, Branco S, Bruns TD, Martin F, Kennedy PG (2019) Genome-based estimates of fungal rDNA copy number variation across phylogenetic scales and ecological lifestyles. Mol Ecol $28,721-730$.

Lu J, Magain N, Miadlikowska J, Coyle JR, Truong C, Lutzoni F (2018) Bioclimatic factors at an intrabiome scale are more limiting than cyanobiont availability for the lichen-forming genus Peltigera. Am J Bot 105, 1198-1211.

McDonald D, Clemente JC, Kuczynski J, Rideout JR, Stombaugh J, Wendel D, Wilke A, Huse S, Hufnagle J, Meyer F, Knight R, Caporaso JG (2012) The biological observation matrix (BIOM) format or: how I learned to stop worrying and love the ome-ome. Gigascience 1, 7.

Millanes AM, Diederich P, Wedin M (2016) Cyphobasidium gen nov, a new lichen-inhabiting lineage in the Cystobasidiomycetes (Pucciniomycotina, Basidiomycota, Fungi). Fungal Biology 120, 14681477.

Moya P, Molins A, Martínez-Alberola F, Muggia L, Barreno E (2017) Unexpected associated microalgal diversity in the lichen Ramalina farinacea is uncovered by pyrosequencing analyses. PLOS ONE 12, e0175091.

Muggia L, Fleischhacker A, Kopun T, Grube M (2016) Extremotolerant fungi from alpine rock lichens and their phylogenetic relationships. Fungal Diversity 76, 119-142.

Muggia L, Grube M (2018) Fungal diversity in lichens: from extremotolerance to interactions with algae. Life 8, 15 . 
Muggia L, Pérez-Ortega S, Kopun T, Zellnig G, Grube M (2014) Photobiont selectivity leads to ecological tolerance and evolutionary divergence in a polymorphic complex of lichenized fungi. Annals of Botany 114, 463-475.

Muggia L, Vancurova L, Škaloud P, Peksa O, Wedin M, Grube M (2013) The symbiotic playground of lichen thalli - a highly flexible photobiont association in rock-inhabiting lichens. FEMS Microbiology Ecology 85, 313-323.

Nilsson RH, Larsson K-H, Taylor AFS, Bengtsson-Palme J, Jeppesen TS, Schigel D, Kennedy P, Picard

Pedregosa F, Varoquaux G, Gramfort A, Michel V, Thirion B, Grisel O, Blondel M, Prettenhofer P,

Petrini O, Hake U, Dreyfuss MM (1990) An analysis of fungal communities isolated from fruticose lichens. Mycologia 82, 444-451.

Pizarro D (2019) Metagenomic sequencing with new bioinformatics approaches to understand the evolution of lichen forming fungi (dissertation). Complutense University of Madrid Complutense University of Madrid, Madrid.

Rognes T, Flouri T, Nichols B, Quince C, Mahe F (2016) VSEARCH: a versatile open source tool for metagenomics. PeerJ 4, e2584.

517 Schoch CL, Seifert KA, Huhndorf S et al (2012) Nuclear ribosomal internal transcribed spacer (ITS) region as a universal DNA barcode marker for fungi. Proceedings of the National Academy of Sciences 109, 6241-6246. doi: 101073/pnas1117018109. tropical and temperate lineages in the ascomycete subfamily Protoparmelioideae (Parmeliaceae).

523 Škaloud P, Moya P, Molins A, Peksa O, Santos-Guerra A, Barreno E (2018) Untangling the hidden intrathalline microalgal diversity in Parmotrema pseudotinctorum: Trebouxia crespoana sp nov. The Lichenologist 50, 357-369. 
Spribille T, Tuovinen V, Resl P, Vanderpool D, Wolinski H, Aime MC, Schneider K, Stabentheiner E, Toome-Heller M, Thor G, Mayrhofer H, Johannesson H, McCutcheon JP (2016) Basidiomycete yeasts in the cortex of ascomycete macrolichens. Science 353, 488-492.

Steinova J, Skaloud P, Yahr R, Bestova H, Muggi, L (2019) Reproductive and dispersal strategies shape the diversity of mycobiont-photobiont association in Cladonia lichens. Mol Phylogenet Evol 134, 226-237.

Tuovinen V, Ekman S, Thor G, Vanderpool D, Spribille T, Johannesson H (2019) Two basidiomycete fungi in the cortex of wolf lichens. Current Biology 29, 476-483e475.

U'Ren JM, Lutzoni F, Miadlikowska J, Arnold AE (2010) Community analysis reveals close affinities between endophytic and endolichenic fungi in mosses and lichens. Microb Ecol 60, 340-353.

Velmala S, Myllys L, Halonen P, Goward T, Ahti T (2009) Molecular data show that Bryoria fremontii and B tortuosa ( Parmeliaceae) are conspecific. The Lichenologist 41, 231-242.

Wang Y, Zheng Y, Wang X, Wei X, Wei J (2016) Lichen-associated fungal community in Hypogymnia hypotrypa (Parmeliaceae, Ascomycota) affected by geographic distribution and altitude. Front Microbiol 7, 1231.

Werth S, Sork VL (2014) Ecological specialization in Trebouxia (Trebouxiophyceae) photobionts of Ramalina menziesii (Ramalinaceae) across six range-covering ecoregions of western North America. Am J Bot 101, 1127-1140.

Wickham H (2016) ggplot2: Elegant Graphics for Data Analysis Springer-Verlag New York

Wickham H, Averick M, Bryan J, Chang W, McGowan L, François R, Grolemund G, Hayes A, Henry L, Hester J (2019) Welcome to the Tidyverse. Journal of Open Source Software 4, 1686. (2018) Endophytic and endolichenic fungal diversity in maritime Antarctica based on cultured material and their evolutionary position among Dikarya. Fungal Systematics and Evolution 2, 263272. 

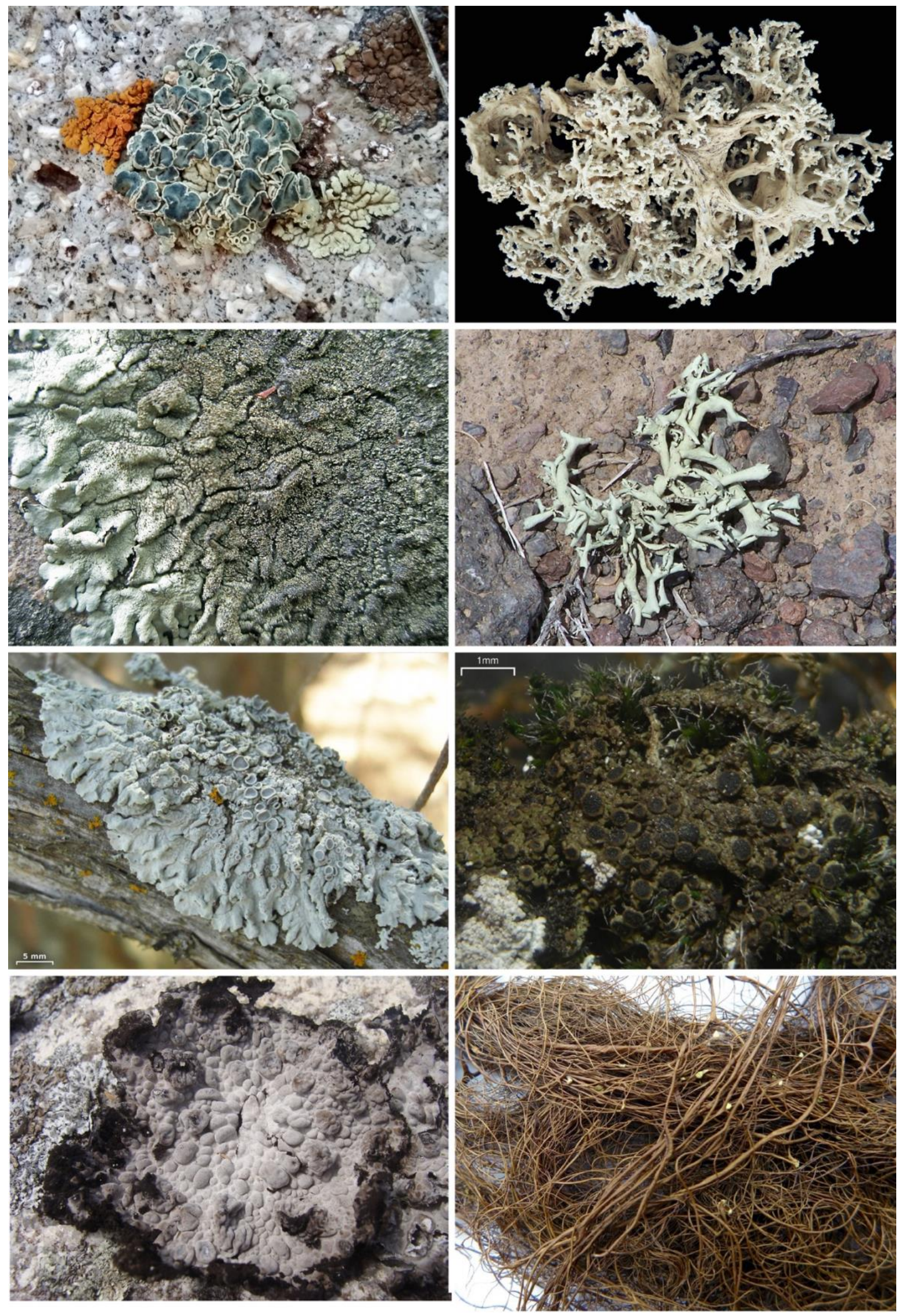
557 Figure 1. Examples of lichens groups considered in this study, including rock posies (A \& B), green rock shields $(\mathbf{C}$

$558 \& \mathbf{D})$, shadow lichens $(\mathbf{E} \& \mathbf{F})$, rock tripe $(\mathbf{G})$, and horsehair lichens $(\mathbf{H})$. A, Rhizoplaca melanophthalma - field

559 image from La Sal Mountain Range, Utah, USA. B, Rhizoplaca arbuscula - collected from Lemhi Valley, Idaho,

560 USA, voucher Leavitt 18-1017 (BRY-C). C, Xanthoparmelia cf. mexicana - field image from Snake Range,

561 Nevada, USA. D, Xanthoparmelia aff. chlorochroa - field image from Awapa Plateau, Utah, USA. E, Physcia

562 biziana - field image from vicinity of Santa Fe, New Mexico (Hollinger 2492). F, Rinodina sp. (I need to track this

563 down). G, Umbilicaria pustulata (I need to track this down). H, Bryoria fremontii (I need to track this down). Note:

564 the name listed for each lichen of the mycobiont (main fungal partner) and does not account for the range of

565 potential other associated symbionts. 
bioRxiv preprint doi: https://doi.org/10.1101/2020.03.04.966853; this version posted March 5, 2020. The copyright holder for this preprint (which was not certified by peer review) is the author/funder, who has granted bioRxiv a license to display the preprint in perpetuity. It is made available under aCC-BY-NC-ND 4.0 International license.

A

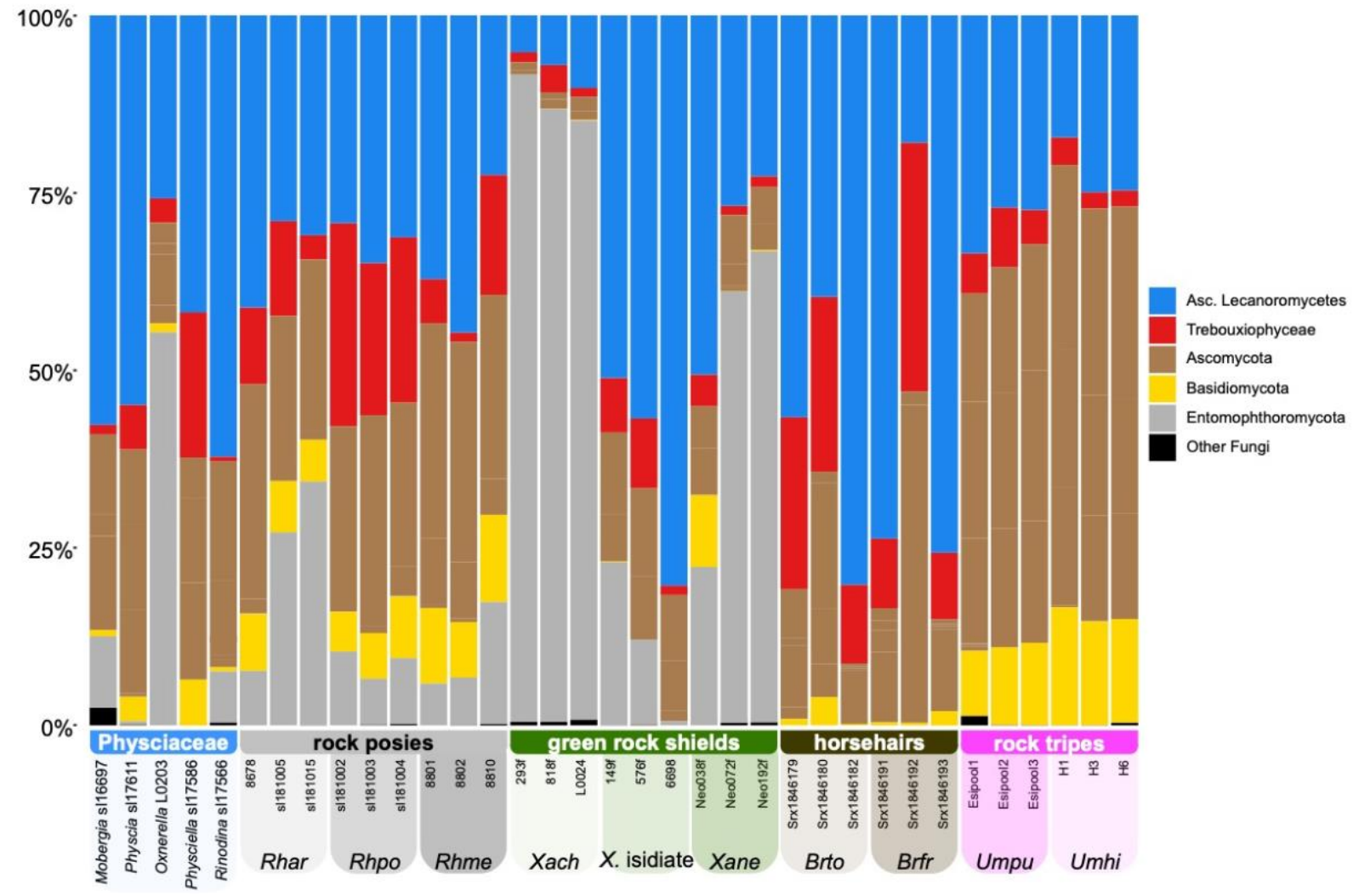

B

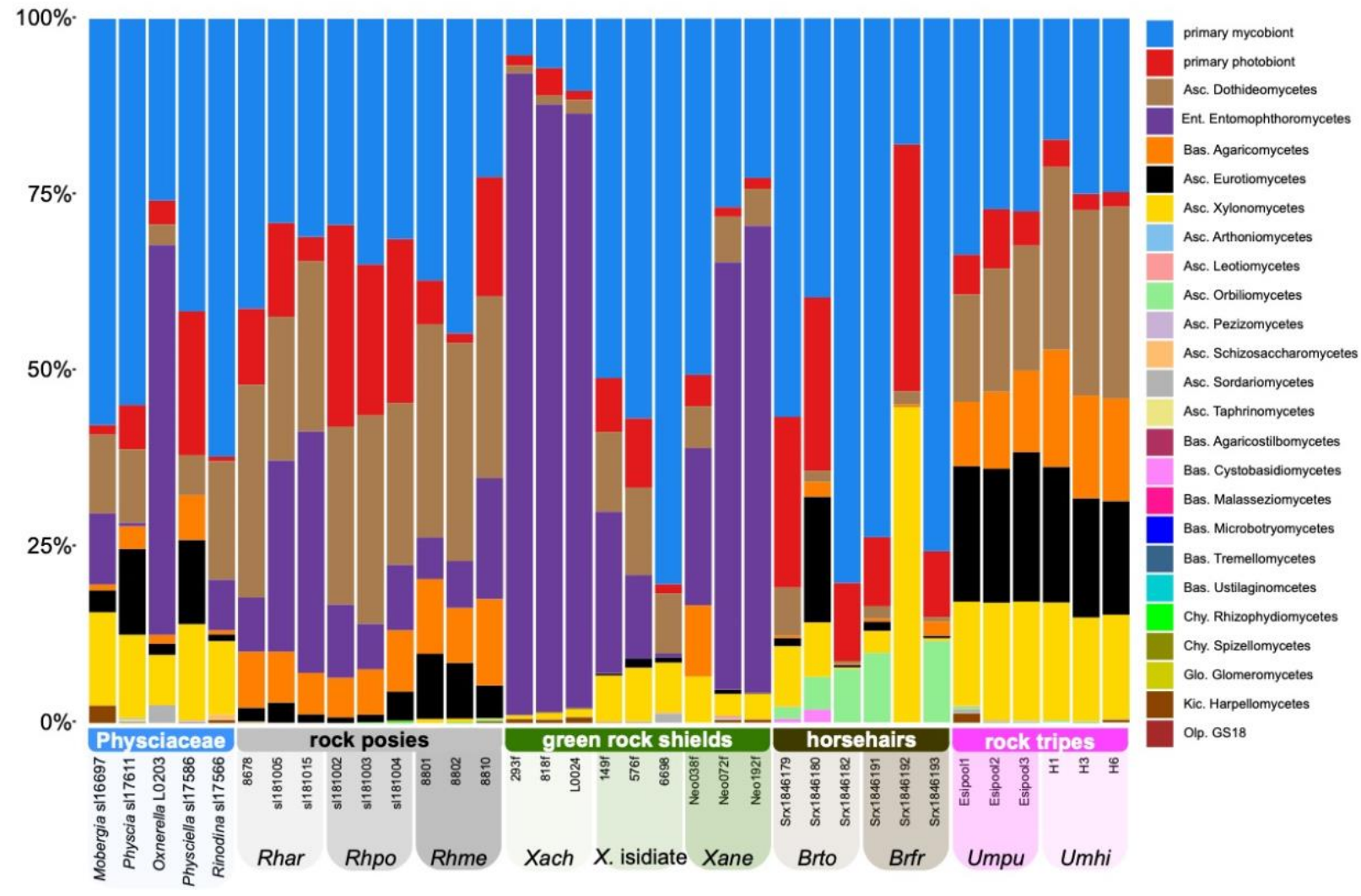


Figure 2. Overview of lichen symbionts and associated fungi inferred from data from the internal transcribed spacer region extracted from metagenomic shotgun sequencing short reads sequenced from lichen thalli representing five different groups of lichens. A, proportion of reads assigned to the lichen symbionts - mycobiont (shown in blue) and photobiont (in red) - and other major fungal lineages. B, same as in panel 'A', but major fungal lineages are broken down and shown at the class level. The five samples at the far left represent lichens associating with different members of the mycobiont family Physciaceae - 'shadow lichens'; 'Rock posies' - in grey - are represented by three species in the mycobiont genus Rhizoplaca, with the first three specimens representing R. arbuscula ('Rhar'), the following three samples are R. melanophthalma subsp. crispa (vagrant forms - 'Rhpo'), and the final three samples represent $R$. melanophthlama (rock-dwelling, fertile forms - 'Rhme'); 'green rock shields' - in green - are represented by three groups in the mycobiont genus Xanthoparmelia, with the first three samples representing $X$. aff. chlorochroa (asexual, vagrant forms - 'Xach'), the next three samples represent isidiate, rock-dwelling forms (' $X$. isidiate'), and the final three samples represent $X$. neocumberlandia (fertile, rock-dwelling forms - 'Xane'); 'horsehairs' - in brown - are represented by two species in the mycobiont genus Bryoria, with the first three samples represent B. tortuosa ('Brto') and the last three, B. fremontii ('Brfr'); 'rock tripes' - in pink - are represented by two groups in the mycobiont genus Umbilicaria, with the first three specimens representing $U$. pustulata ('Uspu')and the last three, U. hispanica ('Ushi'). See supplementary file 1 for a full list of sampled lichens. 
bioRxiv preprint doi: https://doi.org/10.1101/2020.03.04.966853; this version posted March 5, 2020. The copyright holder for this preprint (which was not certified by peer review) is the author/funder, who has granted bioRxiv a license to display the preprint in perpetuity. It is made available under aCC-BY-NC-ND 4.0 International license.

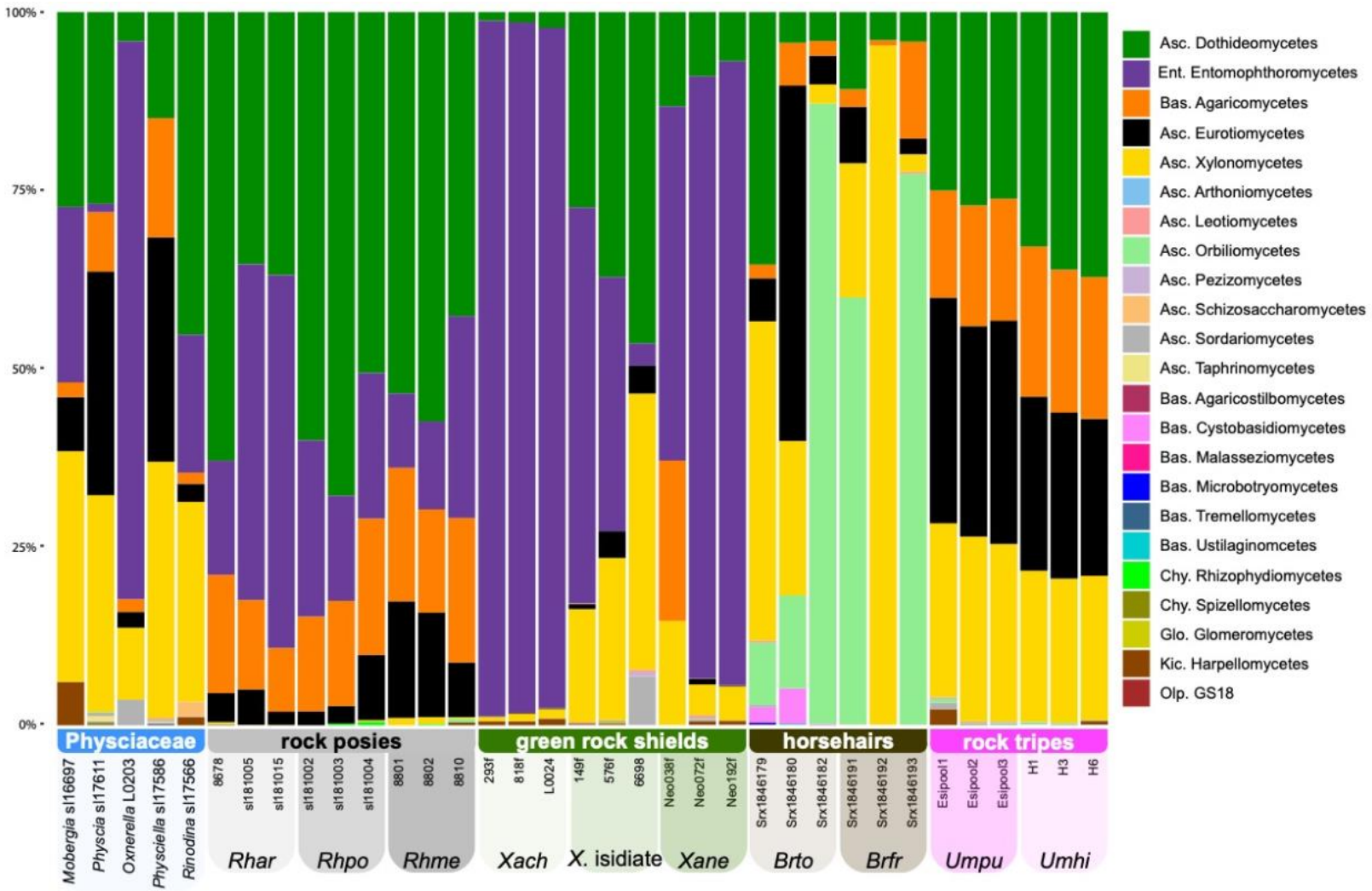

Figure 3. Inferred membership of lichen mycobiomes (at class level) inferred from data from the internal transcribed spacer region extracted from metagenomic shotgun sequencing short reads sequenced from lichen thalli (main lichen symbionts are excluded). The five samples at the far left represent lichens associating with different members of the mycobiont family Physciaceae - 'shadow lichens'; 'rock posies' - in grey - are represented by three species in the mycobiont genus Rhizoplaca, with the first three specimens representing $R$. arbuscula ('Rhar'), the following three samples are R. melanophthalma subsp. crispa (vagrant forms - 'Rhpo'), and the final three samples represent $R$. melanophthlama (rock-dwelling, fertile forms - 'Rhme'); 'green rock shields' - in green - are represented by three groups in the mycobiont genus Xanthoparmelia, with the first three samples representing $X$. aff. chlorochroa (asexual, vagrant forms - 'Xach'), the next three samples represent isidiate, rock-dwelling forms (' $X$. isidiate'), and the final three samples represent X. neocumberlandia (fertile, rock-dwelling forms - 'Xane'); 'horsehairs' - in brown - are represented by two species in the mycobiont genus Bryoria, with the first three samples represent B. tortuosa ('Brto') and the last three, B. fremontii (' $B r f r$ '); 'rock tripes' - in pink - are represented by two groups in the mycobiont genus Umbilicaria, with the first three specimens representing $U$. pustulata ('Uspu')and the last three, $U$. hispanica ('Ushi'). See supplementary file 1 for a full list of sampled lichens. 
bioRxiv preprint doi: https://doi.org/10.1101/2020.03.04 966853; this version posted March 5, 2020. The copyright holder for this preprint (which was not certified by peer review) is the author/funder, who has granted bioRxiv a license to display the preprint in perpetuity. It is made available under aCC-BY-NC-ND 4.0 International license.

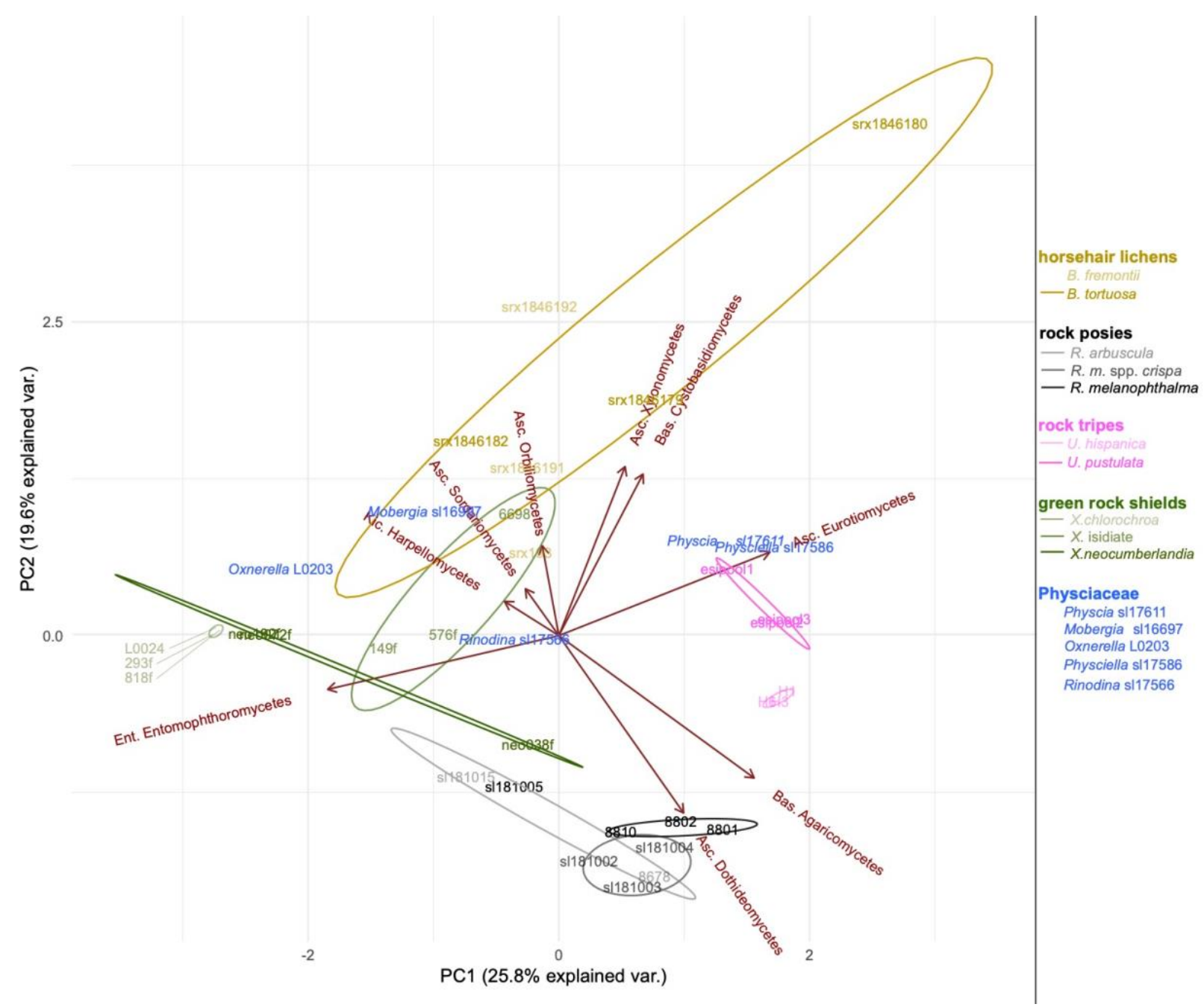

Figure 4. Principal component analysis of lichen mycobiome diversity.

617

618 
bioRxiv preprint doi: https://doi.org/10.1101/2020.03.04.966853; this version posted March 5, 2020. The copyright holder for this preprint (which was not certified by peer review) is the author/funder, who has granted bioRxiv a license to display the preprint in perpetuity. It is made available under aCC-BY-NC-ND 4.0 International license.

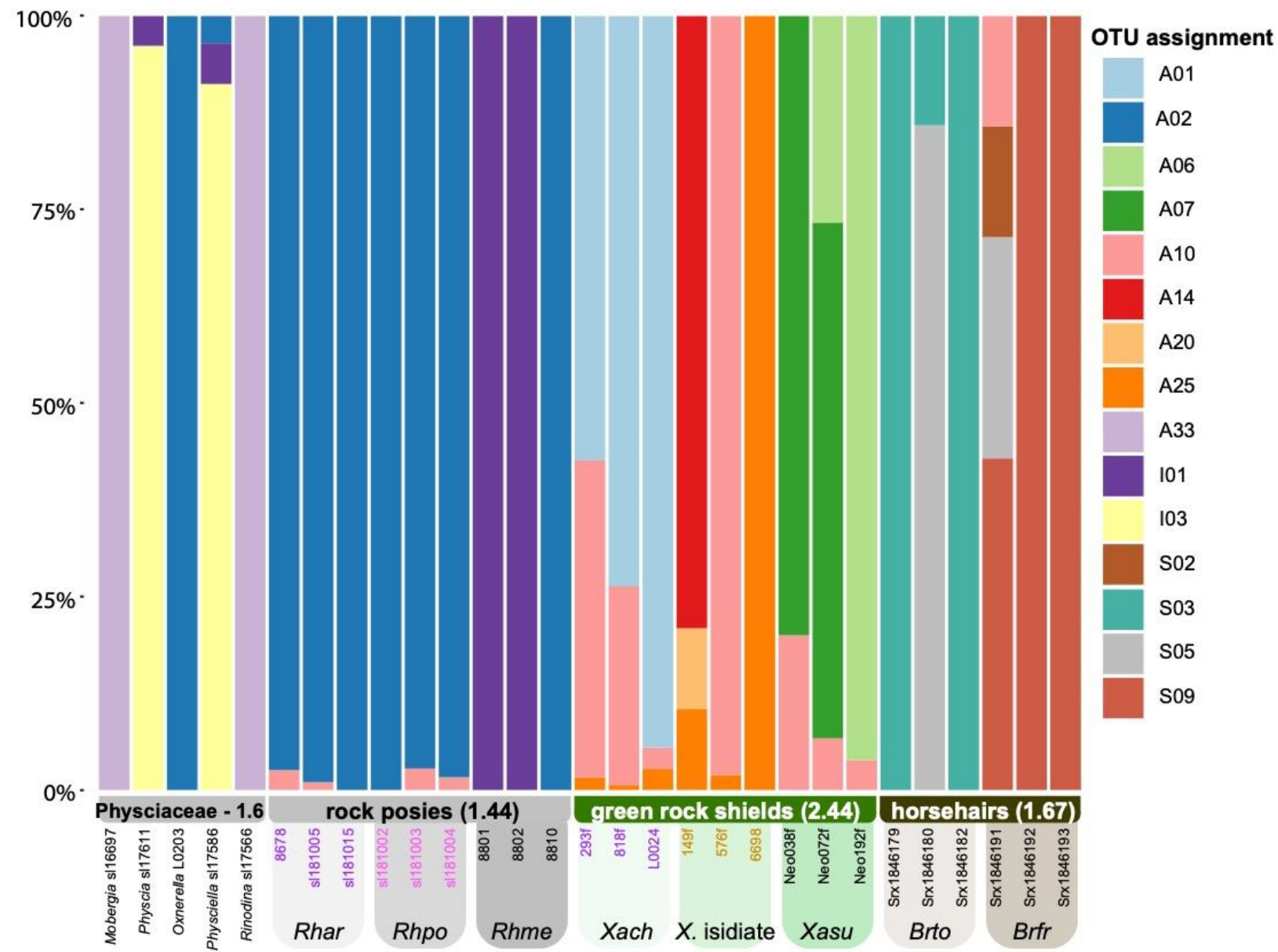

Figure 5. Assessment of intrathalline Trebouxia (photobiont) diversity in four lichen groups. Trebouxia OTUs nomenclature follows Leavitt et al. 2015. 'Rock posies' - in grey - are represented by three species in the mycobiont genus Rhizoplaca, with the first three specimens representing $R$. arbuscula ('Rhar'), the following three samples are $R$. melanophthalma subsp. crispa (vagrant forms - 'Rhpo'), and the final three samples represent $R$. melanophthlama (rock-dwelling, fertile forms - 'Rhme'); 'green rock shields' - in green - are represented by three groups in the mycobiont genus Xanthoparmelia, with the first three samples representing $X$. aff. chlorochroa (asexual, vagrant forms - ' $X a c h$ '), the next three samples represent isidiate, rock-dwelling forms (' $X$. isidiate'), and the final three samples represent $X$. neocumberlandia (fertile, rock-dwelling forms - 'Xane'); and 'horsehairs' - in brown - are represented by two species in the mycobiont genus Bryoria, with the first three samples represent $B$. tortuosa ('Brto') and the last three, B. fremontii ('Brfr'). 